\title{
Body Temperatures in the Elderly: A National Study of Physiological, Social, and Environmental Conditions
}

\author{
R. H. FOX, PATRICIA M. WOODWARD, A. N. EXTON-SMITH， M. F. GREEN， D. V. DONNISON, \\ M. H. WICKS
}

Brisish Medical fournal, 1973, 1, 200-206

The aims were (1) to ascertain the incidence of low body temperatures in the elderly at home during three winter months using recently developed physiological techniques; (2) to relate the body temperatures (hand, mouth, and core) to the environmental temperatures (room and external) and living conditions; and (3) to identify the categories of elderly people particularly at risk of developing hypothermia by investigating the relationships between body temperatures, individuals' awareness of warmth, and socioeconomic circumstances. The results reported here have led us to make such recommendations as seem to be reasonable in the light of this preliminary analysis of the data. duced in this group. Such individuals are at risk of developing hypothermia since they show evidence of some degree of thermoregulatory failure. Further research is needed, but meanwhile there are practical measures that could be taken to reduce the risk of hypothermia in the elderly.

\section{Introduction}

There has been medical concern and public unease for many years about the problem of hypothermia in the elderly but accurate information has been unobtainable, with estimates of the incidence of deaths due to hypothermia varying from the 100 or so returns on the Registrar General's death certificates to over 20,000 deaths yearly (Taylor, 1964). The few surveys which have tried to discover the incidence of low body temperatures have not been national or random and have usually relied on mouth temperature measurements. An estimate that there could have been 9,000 hypothermic patients (of all ages) admitted to hospitals in Great Britain during February, March, and April 1965 (Royal College of Physicians of London, 1966) was based on the criterion of a rectal temperature below $35.0^{\circ} \mathrm{C}$. Many of these patients probably had an associated illness contributing to the fall in body temperature. Furthermore, "many elderly bedridden patients may die in their homes without the condition being diagnosed" (British Medical fournal, 1964).

This paper reports the main results of the first large scale random survey of the elderly population living at home in Great Britain, designed to investigate human and environmental temperatures and factors influencing these temperatures. The survey was undertaken by the Centre for Environmental Studies and the National Institute for Medical Research in collaboration with the geriatric departments of University College Hospital and the Royal Free Hospital. The fieldwork was organized by the Opinion Research Centre.

Division of Human Physiology, National Institute for Medical Research, London NW3 6RB

R. H. FOX, M.B., M.R.C.P., Member of Scientific Staff

PATRICIA M. WWOODWARD, B.SC., Member of Scientific Staff

University College Hospital, London WC1E 6AU

A. N. EXTON-SMITH. M.D., F.R.c.P., Consultant Physician to Department of Geriatric Medicine

Royal Free Hospital, London WC1X 8LF

M. F. GREEN, M.B., M.R.C.P., Consultant Physician to Department of Geriatric Medicine

Centre for Environmental Studies, London N.W.1.

D. V. DONNISON, B.A., Director

M. H. WICKS, B.SC., Member of Staff

\section{Methods}

\section{POPULATION STUDIED AND SELECTION PROCEDURE}

The subjects were selected at random by a systematic probability sample method for the national survey. Over 1,000 subjects were surveyed in 100 constituency sampling points. All constituencies in Great Britain were stratified according to the Registrar General's standard regions and the nature of the constituency - that is, conurbation, borough, or county seat-account being taken of the size of the electorate. In each constituency a clustered systematic sample of voters was drawn from the electoral register. The subjects were visited and those aged 65 and over were invited to co-operate in the survey. This difficult and expensive way of sampling was used as the best method of obtaining a representative sample throughout Great Britain. The sample design was by the Opinion Research Centre (Kish, 1965; Moser, 1971).

In the national survey the fieldwork was spread evenly over three months to ensure that no particular period of time was over-represented or under-represented. A similar largescale study in the London Borough of Camden was carried out with the aim of more intensive domiciliary and hospital investigations on a subgroup.

\section{PHYSIOLOGICAL MEASUREMENTS}

The survey techniques have been described in detail elsewhere (Fox et al., 1971; Fox et al., 1973 a; Fox et al., 1973 b). Briefly, the mouth (usual sublingual position), hand, and urine temperatures were recorded using clinical low-reading thermometers calibrated to $\pm 0.05^{\circ} \mathrm{C}$. The mouth and hand temperatures were measured simultaneously for five minutes. For the hand temperature measurement a clinical thermometer was attached to an expanded polystyrene block; the subject held this with the thermometer pressed against the palm of the hand for five minutes to give the deep tissue temperature rather than that of the skin. The Uritemp bottle (Portex Ltd.) used in a pilot survey (Fox et al., 1973 a) was redesigned with an improved funnel to direct the urine flow over the low-reading thermometer, as described by Fox et al., (1973 b). A disposable urine-temperature measuring device has now been developed.

Our experience in the pilot studies showed the importance of accurate temperature measurement and recording, and a 
magnifying glass was provided to facilitate the reading of the clinical thermometer to the second decimal place.

\section{THERMAL COMFORT AND PREFERENCE GRADINGS}

The subjects' thermal comfort was elicited by the following sets of questions (A, B, and C), which differed from those used in the pilot study (Fox et al., 1973 a). (A) "In general, how warm or how cold are you feeling at the moment?" This was recorded against a scale reading (1) much too warm, (2) too warm, (3) comfortably warm, (4) comfortable, (5) comfortably cool, (6) too cool, and (7) much too cool. (B) "Would your prefer to feel (1) very much warmer, (2) slightly warmer, (3) no change, (4) slightly cooler, or (5) very much cooler?" (C) "How warm or cool do your hands feel at the moment (1) much too warm, (2) too warm, (3) comfortably warm, (4) comfortable, (5) comfortably cool, (6) too cool (7) much too cool?"

The thermal preference scale (B) is closely modelled on the one devised by Watts (1972). This survey differed from the pilot study in that measurements were made at, or as near as possible to, set times in the evening and in the morning.

\section{SURVEY AND QUESTIONNAIRE}

The survey took place during January, February, and March 1972. After an initial visit to ask if the subject was willing to co-operate, morning and evening visits were made as close as possible to set times (8-10 a.m. and 4-6 p.m.) A nurse-interviewer completed a questionnaire with each subject, the procedures being based so far as possible on previous surveys of the elderly, and especially that of Shanas et al. (1968). The main areas of inquiry were the basic demographic situation (age, sex, and marital status), household composition, housing, heating, comfort, contact with medical and social services, degree of isolation, and financial circumstances.

\section{BRIEFING PROCEDURE}

Nurses were recruited in each locality to carry out the interviews and to take the temperature measurements. They were briefed in groups of up to 20 at a time by a combined team of medical, Opinion Research Centre, and Centre for Environmental Studies personnel who went to a number of centres in England and Scotland for this purpose in December 1971. Every question in the questionnaire was considered in turn and the use of the hypothermia kit was described in detail. This kit consisted of a carrier bag containing the Uritemp bottles, a standard whirling hygrometer, mercury in glass thermometers for mouth and hand temperatures, maximum and minimum thermometers for environmental temperatures, disinfectant, magnifying glass, instructions, and notebook. The nurse-interviewers were given supervised practice in the techniques. The medical member of the team took great care to stress the need to handle the interviews sensitively, and if an abnormally low body temperature was found the subject's general practitioner was to be informed immediately.

\section{NATIONAL SAMPLE}

It is important to consider whether the national sample was representative of the elderly population aged 65 and over in Great Britain, and it is possible to make a number of comparisons with data from the census carried out in April 1971 (Office of Population Censuses and Surveys, 1972). The results of the census that are currently available concerning elderly people do not distinguish those in private households from the remainder. However, comparison with the population of old people suggests that the age and sex structure of our sample is representative of the eiderly population as a whole; marital status was generally representative but there was some over-representation of widows and also of those living alone. For various reasons we are not certain how representative the Camden sample will prove to have been.

\section{SOCIAL CHARACTERISTICS OF THE NATIONAL SAMPLE}

The age and marital status of the national sample analysed by sex are shown in tables I and II. Other socioeconomic characteristics of the sample are given in table VIII. Housing tenure differed from the overall British pattern in that $39 \%$ were owner-occupiers compared with $50 \%$ for Britain as a whole, while a correspondingly larger number were renting accommodation either privately or from the local authority. Old people have poorer accommodation than the rest of the population; $24 \%$ of our sample lacked one or more of the basic amenities, compared with $17 \%$ of all dwellings in England and Wales (Department of the Environment, 1972).

Nine per cent. of the respondents were housebound, a figure closely in line with the findings of a study of Shanas et al., (1968). Thirty-four per cent. were receiving supplementary pensions.

TABLE I-Age Distribution of Subjects. National Survey

\begin{tabular}{c|r|r|r|r|r|r}
\hline \multirow{2}{*}{ Age in Years } & \multicolumn{2}{|c|}{ Male } & \multicolumn{2}{c|}{ Female } & \multicolumn{2}{c}{ Total } \\
\cline { 2 - 7 } & No. & $\%$ & No. & $\%$ & No. & $\%$ \\
\hline 570 & 198 & 50 & 248 & 39 & 446 & 44 \\
$71-75$ & 106 & 27 & 178 & 28 & 284 & 28 \\
$76-80$ & 53 & 14 & 98 & 16 & 151 & 15 \\
$>85$ & 24 & 6 & 66 & 10 & 90 & 9 \\
\hline Total & 10 & 3 & 39 & 6 & 49 & 5 \\
\hline
\end{tabular}

TABLE II-Marital Status of Subjects. National Survey

\begin{tabular}{|c|c|c|c|c|c|c|}
\hline & \multicolumn{2}{|c|}{ Male } & \multicolumn{2}{|c|}{ Female } & \multicolumn{2}{|c|}{ Total } \\
\hline & No. & $\%$ & No. & $\%$ & No. & $\%$ \\
\hline $\begin{array}{ll}\text { Married } & \ldots \\
\text { Single } & \ldots \\
\text { Widowed } & \ldots \\
\text { Divorced/separated }\end{array}$ & $\begin{array}{r}289 \\
24 \\
74 \\
4 \\
\end{array}$ & $\begin{array}{r}74 \\
6 \\
19 \\
1 \\
\end{array}$ & $\begin{array}{r}193 \\
79 \\
345 \\
12 \\
\end{array}$ & $\begin{array}{r}31 \\
13 \\
55 \\
2 \\
\end{array}$ & $\begin{array}{r}482 \\
103 \\
419 \\
16 \\
\end{array}$ & $\begin{array}{r}47 \\
10 \\
41 \\
2 \\
\end{array}$ \\
\hline Total & 391 & 100 & 629 & 100 & 1,020 & 100 \\
\hline
\end{tabular}

\section{WEATHER CONDITIONS DURING THE SURVEY}

Mean environmental temperatures for the survey period were obtained from the Meteorological Office and compared with a 25 -year average. This showed that the weather was slightly milder than normal (table III).

TABLE III-Average Outdoor Temperatures $\left({ }^{\circ} \mathrm{C}\right)$ during the Survey Period. (Source: Meteorological Office)

\begin{tabular}{ll|c|c|c}
\hline & & January & February & March \\
\hline England and Wales & $\{1972$ & $4 \cdot 5$ & $5 \cdot 0$ & $7 \cdot 0$ \\
Scotland & Previous 25 years & $4 \cdot 3$ & $4 \cdot 5$ & $6 \cdot 4$ \\
& $\left\{\begin{array}{l}\text { Previous 25 years } \\
\end{array}\right.$ & $4 \cdot 5$ & $4 \cdot 3$ & $5 \cdot 7$ \\
& & $3 \cdot 9$ & $5 \cdot 4$ \\
\hline
\end{tabular}

\section{ANALYSIS OF DATA}

Clinical Data-All temperatures were screened to exclude values that were clearly not reflecting true situations. Fevers: If the urine and mouth temperatures were both $38.0^{\circ} \mathrm{C}$ 
or more and the hand was not cold all clinical data for the subject were omitted. Effect of Hot Drinks on Mouth Temperature: Data were excluded if a drink had been taken within half an hour of the temperature being measured and the temperature recorded was more than $38.0^{\circ} \mathrm{C}$ or was more than $1.0^{\circ} \mathrm{C}$ higher than the urine. Hand: Data were excluded if the hand temperature was more than $0.5^{\circ} \mathrm{C}$ above both the corresponding mouth and urine temperatures (hand temperatures below $24.0^{\circ} \mathrm{C}$ had not been recorded by the nurses). Urine: Data were excluded if the urine volume was less than $50 \mathrm{ml}$. If the volume was between 50 and $99 \mathrm{ml}$ the data were included if the temperature was (a) greater than $35.5^{\circ} \mathrm{C}$ or $(b)$ less than $35.0^{\circ} \mathrm{C}$ and the mouth and hand temperatures were correspondingly low. Data were also excluded if the urine temperature was at least $2.0^{\circ} \mathrm{C}$ lower than the mouth in the morning or at least $1.0^{\circ} \mathrm{C}$ lower in the afternoon (a wider limit had to be set for morning data as some collections were made earlier than recommended (8-10 a.m.)).

Survey Data.-Every effort was made to remove inconsistent data such as "never went out" when the diary for the previous day said "visited friends" or "went shopping." In all the analyses the national and Camden data were treated separately. The significant or nonsignificant differences were established by the use of correlations and the $\chi^{2}$ and $t$ tests.

Classifications of Subjects.- The subjects were divided into two classes according to their morning urine temperatures. Subjects with temperatures of less than $35.5^{\circ} \mathrm{C}$ were the "low old" and those with temperatures equal to or greater than $36.0^{\circ} \mathrm{C}$ (excluding fevers) the "normal old." These groups are referred to below as "low" and "normal" respectively.

\section{Results}

The brief comments that follow on the results analysed so far are an attempt to link together the way separate factors influence the deep body temperature of the elderly.

Frequency Distributions for Body and Environmental Temperatures.-The morning body and environmental temperatures for the national sample are illustrated in fig. 1 (a, b, c, and d). The apparently abnormal distribution for hand temperature is due to the fact that the highest temperature category includes all readings above $35.0^{\circ} \mathrm{C}$. The tendency of the mouth and urine temperatures to peak at $35.0^{\circ} \mathrm{C}$ may be due to observers "rounding up" temperatures near to $35.0^{\circ} \mathrm{C}$.

Room Temperatures.-The distribution of living room temperatures at the time of the nurses' morning visit is given in fig. 1 (d). Clearly many of the rooms were much too cold for comfort. In 754 cases $(75 \%)$ the temperatures were at or below $18.3^{\circ} \mathrm{C}\left(65.0^{\circ} \mathrm{F}\right)$, the minimum level recommended by the Parker Morris report on council housing (Ministry of Housing and Local Government, 1961); the proportion is even greater if the $21 \cdot 1{ }^{\circ} \mathrm{C}\left(70.0^{\circ} \mathrm{F}\right)$ recommended for old people by a recent Department of Health and Social Security (1972 b) leaflet as applied. In 537 cases (54\%) the temperatures were at or below $16.0^{\circ} \mathrm{C}\left(60.8^{\circ} \mathrm{F}\right)$, the minimum temperature specified in the Offices, Shops and Railway Premises Act (1963). A number of subjects were living in exceedingly cold conditions. In 106 cases (10\%) morning living-room temperatures were at or below $12.0^{\circ} \mathrm{C}\left(53.6^{\circ} \mathrm{F}\right)$.

Mean Morning and Evening Temperatures.-The physiological measurements obtained in the national and Camden surveys were closely comparable-for example, the mean morning mouth temperatures showed a difference of only $0.06^{\circ} \mathrm{C}$ (table IV). The slightly higher mean environmental temperatures recorded in the Camden survey were due to the fact that a larger number of subjects were studied in the warmer month of March. The differences between the morning and evening body temperature measurements illustrated a marked circadian rhythm in this elderly population.

TABLE IV-Average Body and Environmental Temperatures $\left({ }^{\circ} \mathrm{C}\right)( \pm S . D$. in the Morning and Afternoon. National and Camden Surveys.

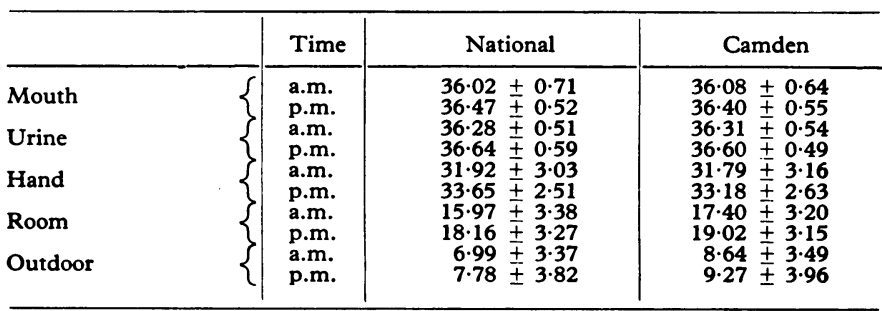

Body Temperature and Age Correlations.-Correlations between the various temperatures and between age and temperature are given in table $\mathrm{V}$. The pattern of significance and non-significance was similar in the two surveys. The deep body or "core" temperature, as measured by the urine technique, did not appear to be related to either the room or external temperature whereas it was significantly correlated with the other body temperatures. This indicates that for the group as a whole the thermoregulatory mechanisms were maintaining deep body temperature homoeostasis, although at a lower level than in younger individuals. Mouth temperature

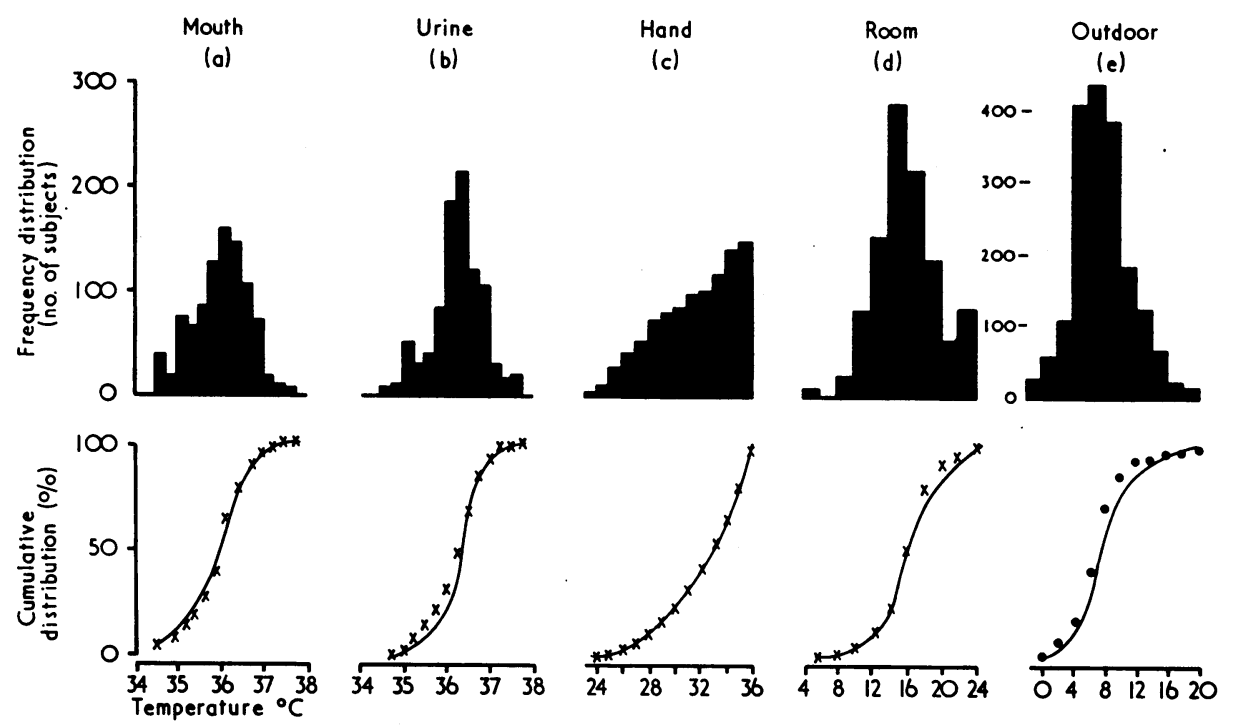

FIG. 1-Frequency distributions of morning body and room temperatures (a-d) (national survey) and outdoor temperatures (e) (national and Camden surveys). The first and last block of each distribution represent all data less than or greater than those in their adjacent blocks. Cumulative distributions (a) to (d) distinguish between the sexes, and the fifth distribution (e) between the national and Camden outdoor temperatures; in (a) to (d) " $x$ " indicates females and the solid line males, and in (e) " $"$ " indicates Camden survey and the solid line national survey. 
ABLE V-Correlation between Temperatures and between Temperature and Age. National $(N)$ and Camden $(C)$ Surveys

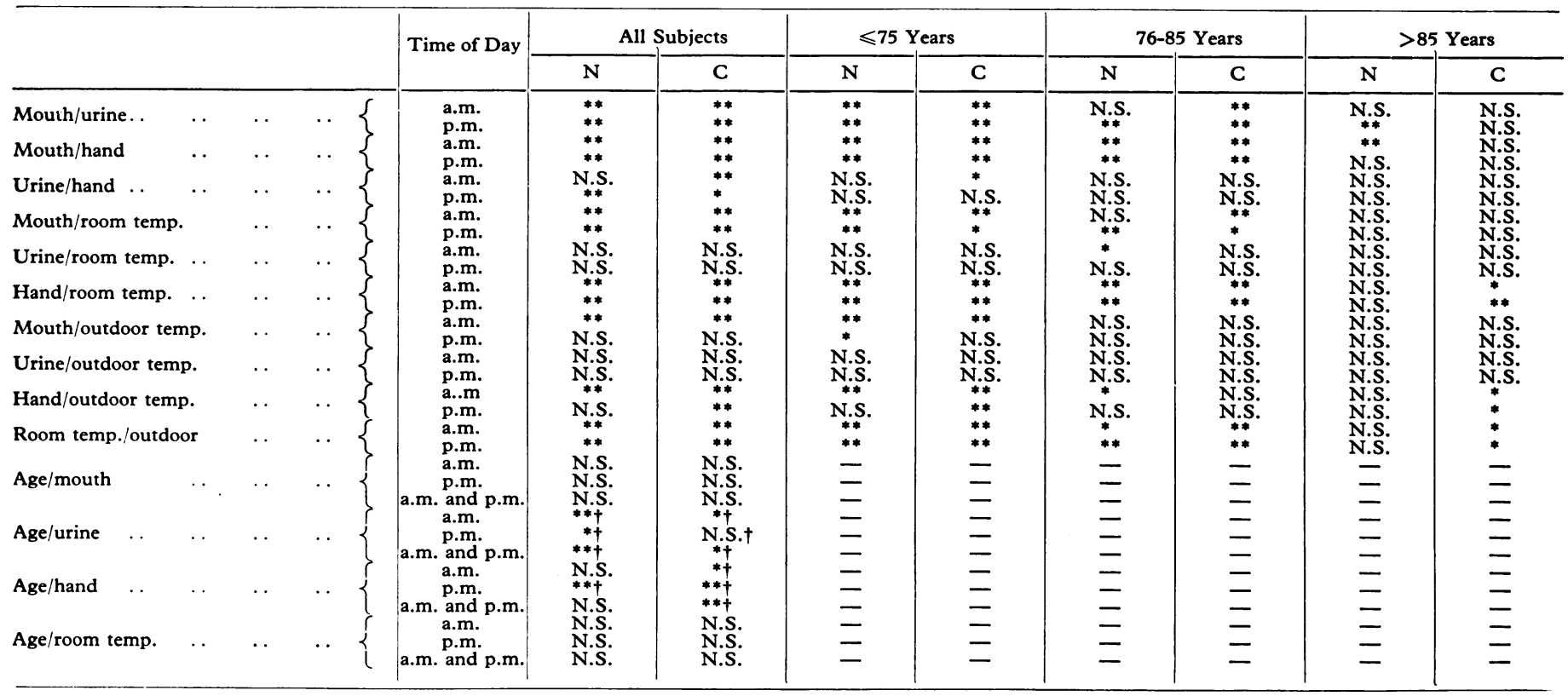

N.S. $=$ Not significant. $\quad * 0.05>P \geqslant 0.01 . \quad * * P<0.01 . \quad+$ Negative correlation.

is influenced by both room and external air temperatures. The significant correlations found between the hand and all the other temperatures reflect the important role of the peripheral parts of the body in thermoregulatory control. The relationships between the body temperatures and age are of great interest. Urine and hand temperatures showed a negative correlation with age $(P<0.01)$, whereas the correlation of mouth and room temperatures seemed unaffected by advancing age. The absence of a relation between room temperature and age seems to exclude one hypothesis for the decline in deep body temperature with age-namely, that it is simply due to the older people living in colder accommodation. Furthermore, the decrease in hand temperature with age shows that they seemed to be making greater attempts to conserve body heat.

"Normal" and "Low" Temperature Group Comparisons.When comparing the low deep body temperature group $\left(<35.5^{\circ} \mathrm{C}\right)$ with the normal group $\left(>36.0^{\circ} \mathrm{C}\right)$ only the mouth temperatures were found to differ significantly. However, the low group did have slightly warmer hand temperatures (national survey) and were in somewhat cooler rooms. Thus they appeared to be exhibiting some degree of thermoregulatory failure or inadequate response to cooler surroundings (table VI).

TABLE VI-Average Morning Body and Environmental Temperatures $\left({ }^{\circ} \mathrm{C}\right.$ ) $(+$ S.E. $)$ in the "Low" and "Normal" Groups of Subjects. National Survey

\begin{tabular}{c|c|c}
\hline & $\begin{array}{c}\text { "Low" } \\
\left.\text { "L.m. Urine }<35.5^{\circ} \mathrm{C}\right)\end{array}$ & $\begin{array}{c}\text { "Normal" } \\
\left.\text { "a.m. Urine } \geqslant 36.0^{\circ} \mathrm{C}^{*}\right)\end{array}$ \\
\hline No. of Subjects: & 97 & 699 \\
\hline Mouth ${ }^{\circ} \mathrm{C}$ & $35.83 \pm 0.07$ & $36.06 \pm 0.03$ \\
Hand $^{\circ} \mathrm{C}$ & $32.24 \pm 0.30$ & $31.90 \pm 0.12$ \\
Room $^{\circ} \mathrm{C}$ & $15.56 \pm 0.35$ & $15.98 \pm 0.13$ \\
Outdoor $^{\circ} \mathrm{C}$ & $7.39 \pm 0.31$ & $7.06 \pm 0.13$ \\
\hline
\end{tabular}

* Excluding fevers.

Comfort Votes.-Comfort gradings for the low and normal urine temperature groups are shown in table VII. As a significant sex difference was not found the results for both sexes were combined. There was no significant difference in the general body comfort between the two groups but there was a significant difference in the pattern of response for hand comfort, the low group generally saying their hands were colder. The preference votes showed that both groups wanted to be warmer, with a marginally greater emphasis by the low group. For two of the three comfort vote questions there were large numbers of subjects who regarded themselves and their hands as "cool" to "much too cool." The differences between gradings of general body comfort and hand comfort are illustrated in table VII. It was striking how the majority of both groups would have preferred to be warmer, although about half had already said they were warm.

TABLE VII-Percentage Distribution of Comfort Votes among the "Low" and "Normal" Groups of Subjects. National Survey

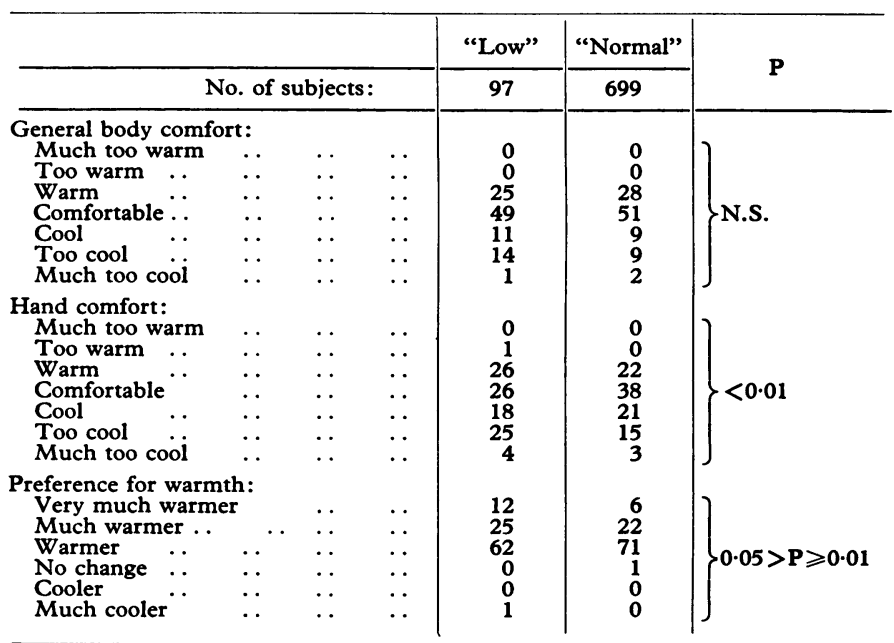

Socioeconomic Circumstances.-The deep body temperatures analysed with a number of social and economic factors are shown in table VIII. The only significant factor to emerge is the receipt of supplementary pensions. This factor broadly distinguishes the poorest one-third of the sample and therefore strongly suggests that low income is associated with low body temperature. Further analysis will be necessary to supplement this simple comparison of body temperatures with single socioeconomic factors. 
TABLE VIII-Socioeconomic Characteristics of the "Low" and "Normal" Groups of Subjects. National Survey. Numbers represent the Percentage of Subjects in Each Group who Answered Question

\begin{tabular}{|c|c|c|c|c|c|c|}
\hline & & & & "Low" & "Normal" & \multirow{2}{*}{$\mathbf{P}$} \\
\hline \multicolumn{4}{|c|}{ No. of subjects: } & 97 & 699 & \\
\hline \multirow{3}{*}{$\begin{array}{l}\text { Living alone } \\
\text { Mobility: } \\
\text { Housebound } \\
\text { Ambulant } \quad .\end{array}$} & . & . & .. & 40 & 32 & N.S. \\
\hline & .. & . & . & 12 & 7 & V.S. \\
\hline & \multicolumn{2}{|c|}{ Housing tenure: } & & 88 & 93 & \\
\hline Owner-occupied & .. & .. & .. & 31 & 40 & \\
\hline Local authority & .. & . & .. & 49 & 37 & SN.S. \\
\hline $\begin{array}{l}\text { Privately rented } \\
\text { Others }\end{array}$ & $\cdots$ & . & .. & 18 & 20 & \\
\hline \multirow{2}{*}{\multicolumn{7}{|c|}{$\begin{array}{l}\text { Lack of one or more of: } \\
\text { Fixed bath, kitchen sink, inside } \\
\text { W.C., hot water at bath, sink, }\end{array}$}} \\
\hline & & & & & & \\
\hline $\begin{array}{l}\text { and hand-basir } \\
\text { Central heating }\end{array}$ & & . & * & 30 & 26 & N.S. \\
\hline \multicolumn{4}{|c|}{ Supplementaty pensions: } & & & \\
\hline $\begin{array}{l}\text { Receiving } \\
\text { Not receiving }\end{array}$ & . & . & . & 50 & 33 & \}$<0.01$ \\
\hline \multirow{2}{*}{\multicolumn{4}{|c|}{$\begin{array}{l}\text { Heat in bedroom: } \\
\text { All night or before going to bed .. }\end{array}$}} & & & \\
\hline & & & & 36 & 38 & N.S. \\
\hline None & 然 & .. & .. & 57 & 48 & \\
\hline
\end{tabular}

Hypothermia.-Hypothermia is generally defined as a deep body temperature of $35.0^{\circ} \mathrm{C}$ or below measured rectally (Royal College of Physicians, 1966), but it has been shown (Fox et al., 1971) that the corresponding urine temperature is approximately $34.8^{\circ} \mathrm{C}$. After exclusions resulting from our statistical screening there were 28 subjects who had urinary temperatures of $35.0^{\circ} \mathrm{C}$ or below in the morning; 13 of these were below $34.8^{\circ}$. Nineteen subjects had mouth temperatures more than $1.0^{\circ} \mathrm{C}$ above their urine temperatures, and these were excluded too. A low urine temperature in subjects with a falsely high mouth temperature (due, for example, to a recent hot drink) could still have indicated hypothermia, but there was no way of distinguishing this group from those in whom the low urine temperature was the result of a fault in technique. There remained a total of nine subjects who had abnormally low deep body temperatures in the morning, but all were above the hypothermic level in the evening. Five of the nine had morning mouth temperatures above $35.0^{\circ} \mathrm{C}$, but the highest of these was only $35 \cdot 25^{\circ} \mathrm{C}$.

Analysis of the Nine Subjects with Morning Low Body Temperature.- Of the 9 subjects 5 (4 national, 1 Camden) had urine temperature of $34.8^{\circ} \mathrm{C}$ or below, and 4 (2 national, 2 Camden) had urine temperatures of $34.8^{\circ}$ to $35.0^{\circ} \mathrm{C}$. Some of the important characteristics of the subjects with very low deep body temperatures were as follows: most were living alone, had no heating in the bedroom, and lacked the basic amenities of hot water in the bath, sink, and basin; all were single or widowed; none had central heating; five had no help from community services, but the needs of the remaining four were partly recognized by attention from district nurses, health visitors, or home helps; and seven were receiving supplementary pensions. Their room temperatures were similar to the overall mean (national). The hypothermic subjects did not have a higher mean hand temperature that that for all subjects. The hypothermic subjects represented $0.58 \%$ of the national and $0.32 \%$ of the Camden samples. Those with a deep bndy temperature below $35.5^{\circ} \mathrm{C}$ represented $9.5 \%$ of the national and $10.0 \%$ of the Camden samples, and we believe that it is much more important to focus attention on this large group, who have only small reserves of body heat. The mean urine temperature for the low group was $35.1^{\circ} \mathrm{C}$ and that for the normal group $36.5^{\circ} \mathrm{C}$, so that the core to periphery temperature gradient was $2.9^{\circ} \mathrm{C}$ in the low group and $4.6^{\circ} \mathrm{C}$ in the normal group (fig. 2). This indicates a degree of themoregulatory inadequacy in the low group compared with the normal group. Fig. 2 shows the significant correlations between temperature measurements and summarizes the separate socioeconomic and physiological factors we have tested.

\section{Discussion}

The deep body temperature of the elderly population is the most important aspect of this study. The results of the mouth and urine temperature measurements are compared in fig. 3 with those reported in some other investigations of old people and fit young adults (Ivy, 1944; Fox et al., 1971; Salvosa et al., 1971; Fox et al., 1973 a).

The mean deep body temperatures of the elderly in the two surveys and the earlier pilot study are remarkably close. The greater variability of the results from the pilot survey was due to combining both morning and evening measurements, which underlines the importance of taking into account the circadian rhythm in any evaluation of body temperatures. In contrast the younger subjects showed a higher mean deep body temperature, and the corresponding standard deviations were based on the mean for each subject. The comparison of mouth temperatures in these studies shows a similar pattern at a lower temperature but with a much more marked effect of cold exposure in the young adults. The greater

(4) Seporate correlations with decreasing body T. a.m.

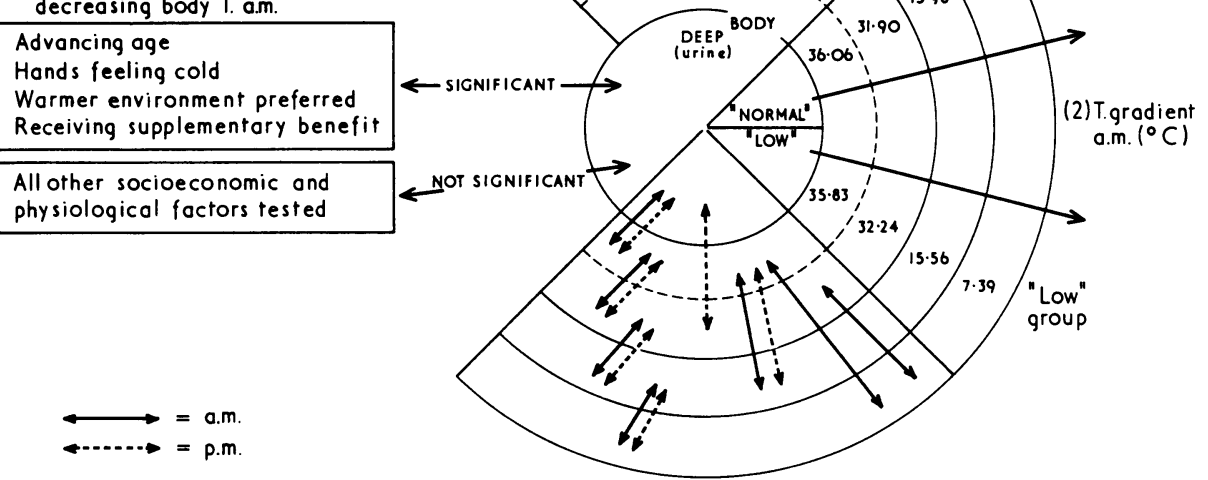

(3) Significant T. correlations FIG. 2-Body and environmental temperature (1) Summary of many important relationships between temperatures forming gradient from botween temperatures forming gradient from parison of the mean (a.m.) temperatures $\left({ }^{\circ} \mathrm{C}\right.$ ) for the "low" and "normal" groups. (3) Significant correlations (a.m., p.m.) between temperatures. (4) Important significant correlations with certain physiological and socioeconomic factors. 


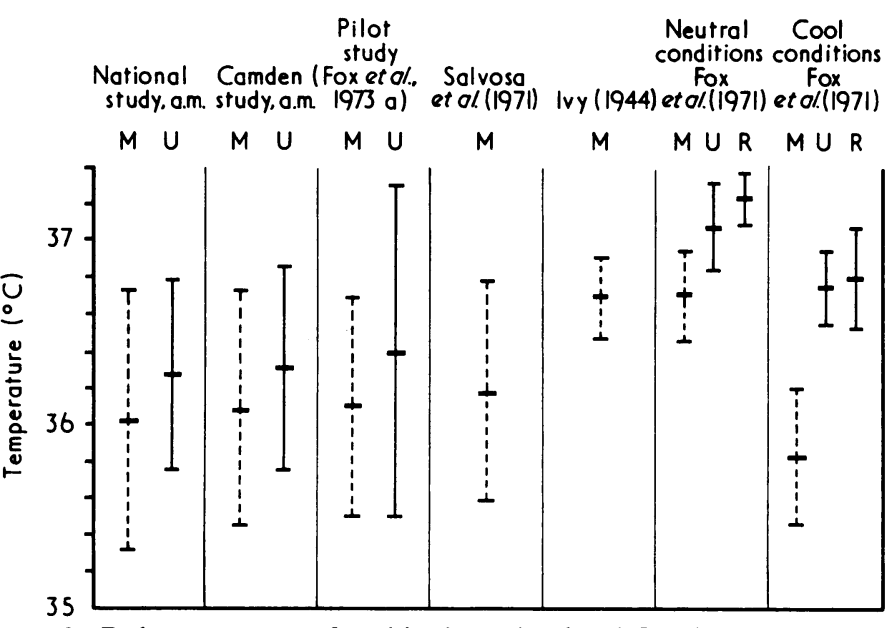

FIG. 3-Body temperatures found in the national and Camden studies compared with results of earlier studies on elderly individuals and young adults (neutral and cold conditions). Means and standard deviations are shown. $\mathbf{M}=$ Mouth. $\mathrm{U}=$ Urine. $\mathbf{R}=$ Rectal.

variability of the measurements in the elderly is probably an effect of ageing, commonly found in measurements of function in other bodily systems.

The value of the urine temperature technique is apparent from the more significant correlations shown by this measurement compared with those obtained when mouth temperature is used. With the addition of the hand temperature measuring technique thermoregulatory control is open to logical analysis (Fox et al., 1973b). As this survey was carried out during a slightly milder winter than usual it is important to realize that the number of cases found with low body temperatures could be an underestimate rather than an overestimate of those that occur on average. Our elderly subjects may have been affected during the survey period by a miner's strike ( 9 January to 28 February) and reductions in the power supplies.

A feature of this study was that we did not find a high incidence of hypothermia in the elderly at home; however, large numbers of old people with low deep body temperatures were found. These people are "at risk" not only because they are less successful in conserving body heat, as shown by their inability to maintain an adequate core/shell temperature gradient, but also because they have a proportionately lower body heat content. This study underlines the lack of awareness of cold by some old people (Watts, 1972; Fox et al., 1973a). Individual attitudes, the acceptance if hardship by old people, and difficulties with communication may all play a part; but we cannot exclude some degree of failure of thermal perception. The extent of this problem is shown by the remarkable disparities not only between body temperatures and comfort votes but also when the replies concerning general body warmth are compared with the preference for greater warmth.

So far the only single factor to have any appreciable predictive or explanatory value that has emerged from the analysis of the socioeconomic situation is receipt of supplementary benefits; this shows that we are likely to be dealing with a complex multicausal situation. These benefits offer a crude means of identifying poorer old people since they are allocated according to a carefully administered means test, but we must beware of simple interpretations. While poor people are likely to be cold because they live in poor housing and spend too little on fuel, their temperature and poverty may be influenced by other factors, such as extreme old age. The cost of fuel is undoubtedly a major worry for old people; 375 of our respondents replied "Yes" to the question "Would you generally like to have more heat in the house?" They were then asked "Why do you not have more heating?", and $91 \%$ of them gave "too expensive" as a reason.
There is a disturbingly large number of individuals with low body temperatures who are already receiving supplementary benefits. The Supplementary Benefits Commission considers that the basic benefit scale rates cover "all normal needs," including fuel (Department of Health and Social Security, 1972a). The Commission also has discretionary power to award a weekly addition for extra heating in certain circumstances. In our national survey only $3 \%$ of pensioners in receipt of supplements said that they were receiving a fuel allowance. In answer to the question "Do you know that in certain circumstances old people can get extra money for heating?" $74 \%$ of those asked (333 persons) replied "No." Obviously the availability of extra heating allowances and the circumstances in which they are available need greater publicity. The Department of Health and Social Security (1972c) leaflet Provision for Heating is helpful in this respect but is not sufficient by itself.

Our findings are in agreement with previous studies (Society of Medical Officers of Health, 1968; Williams, 1968; Allen, 1969; Eddy et al., 1970; Corkhill et al., 1972) in showing the prevalence of low room temoeratures, especially in the morning. It was the morning measurements that showed most clearly the seriousness of the problem of the old in the cold winter months. Deep body temperatures rose during the day so that none of the nine individuals who were classified as "hypothermic" on the basis of their morning temperature readings had a deep body temperature below $35.0^{\circ} \mathrm{C}$ in the evening. Measures directed towards protecting the individual from cold exposure at night would therefore seem most logical. A practical approach would be the provision of a low-wattage electric under-blanket for the elderly at risk. The blanket should be specially designed for this purpose and constructed so that it can be left on continuously at a low heat output and is waterproof and electrically safe. It could be installed and periodically supervised by the community nursing service. Warning systems capable of detecting and communicating to a distant monitor a serious decrease in room temperature or even deep body temperature (using new thermistor thermometer devices for measuring urine temperature now being developed at the National Institute for Medical Research (unpublished)) could also be especially valuable during the night.

The use of a limit of $35.0^{\circ} \mathrm{C}$ rectal $\left(34.8^{\circ} \mathrm{C}\right.$ urine) to define hypothermia is helpful in making comparisons with the few other clinical studies (these include those by Duguid et al., 1961; Rosin and Exton-Smith, 1964; Royal College of Physicians, 1966) which have shown an increasing mortality and morbidity associated with progressive lowering of deep body temperatures below $35.0^{\circ} \mathrm{C}$. Although the choice of $35.0^{\circ} \mathrm{C}$ as the lower limit of normality is partly justified by clinical experience, we have shown that individuals can have deep body temperatures fluctuating above and below this arbitrary level, and thus the classification of hypothermia would depend on the time of day that the temperature is taken.

We therefore believe that it is most unwise to make firm projections of the incidence of hypothermia for the population as a whole. Furthermore, the hypothermia in our two groups of subjects is based on a temperature difference of $0.2^{\circ} \mathrm{C}$, which clearly has relatively little biological significance. These considerations raise a number of important points. We need to know more about the morbidity and mortality of patients admitted to hospital with low body temperatures complicating other clinical conditions. We should also know the level of deep body temperature maintained for a given duration at which there is likely to be a serious degree of physiological and biochemical disturbance.

Finally, deeper analysis of the results may show further significant relationships between the physiological and socioeconomic data. This is a complex and time-consuming task and should not be attempted piece-meal. It is hoped that we will be able to report such additional findings next autumn. 


\section{Recommendations}

(1) A survey using measuring techniques similar to those used in the present study should be undertaken on large groups of younger subjects. This would provide data with which the results of the present study could be compared. It would also help doctors in establishing the criteria for "normality" in other clinical situations.

(2) The Royal College of Physicians's (1966) hypothermia survey should be repeated using similar procedures to those used in the present study and including a follow-up of the progress of random samples of patients aged 65 years and over in the categories "low" and "normal" as adopted here. This would help to elucidate the problem of the effect of body temperature on morbidity and mortality.

(3) For the diagnosis of the illness hypothermia the deep body temperature must be measured.

(4) The definition of the illness hypothermia should be carefully considered at the next revision of the classification of diseases adopted by the Registrar General and the World Health Organization. All patients who are known to have had a deep body temperature below $35.0^{\circ} \mathrm{C}$ during their illness should have this fact recorded for the purposes of hospital activity analysis and death certification.

(5) A small co-ordinating committee consisting of medical and social scientists and administrators should be set up to consider the cost-effectiveness, practicability, and usefulness of a variety of measures, some of which are indicated below.

(6) Priority should be given to the consideration of measures which will help to ensure that elderly people are not precluded by lack of money from attaining living conditions adequate to protect them from the cold.

(7) Other approaches to the problem could also be of great benefit if they were effectively promoted and applied: (a) the development and use of warning systems to detect either low room or low body temperatures or both; $(b)$ the development and use of a low-wattage electric under-blanket designed for this purpose; (c) measures to improve space heating and insulation in the homes of those at risk; (d) the lower limit on the standard clinical thermometer should be extended downwards from $35.0^{\circ} \mathrm{C}$ to 32.0 or $33.0^{\circ} \mathrm{C}$.

(8) Doctors and others in contact with the elderly should pay particular attention to old people living in cold accommodation with low deep body temperatures even though they say they do not feel the cold.

(9) More effective publicity is needed to ensure that the elderly and those responsible for their welfare know about the many measures already available to meet their needs.

In such a large scale multidisciplinary, multicentre study it is impossible to acknowledge adequately all the help received. Never- theless, we thank the Nuffield Foundation for so generously providing most of the finance required; the Joseph Rowntree Memorial Trust for supporting one of the pilot surveys; and Shell-Mex and BP and the Electricity Council. The study owes a great deal to the staff of the Opinion Research Centre, especially John Hanvey, and also the staffs at the Medical Research Council Computer Unit, the division of Human Physiology, and the Centre for Environmental Studies. We also thank Dr. A. S. V. Burgen and Dr. O. G. Edholm for their advice and help. We owe a special debt of gratitude to the nurses, but our major thanks must go to all the old people who participated.

Inquiries about the disposable urine-temperature measuring device and a low-wattage electric under-blanket for the elderly may be made to the National Research Development Corporation.

Requests for reprints should be addressed to Dr. R. H. Fox.

\section{References}

Allen, W. H. (1969). Public Health (London), 83, 229.

British Medical fournal, 1964, 2, 1255.

Corkhill, R. T., Holland, W. W., Fox, R. H., and Mee, M. S. R. (1972). British fournal of Preventive and Social Medicine, 26, 40.

Department of Health and Social Security (1972a). Supplementary Benefits Handbook, London, H.M.S.O

Department of Health and Social Security (1972b). Keeping Warm in Winter. London, H.M.S.O.

Department of Health and Social Security (1972c). Provision for Heating. London, H.M.S.O

Department of the Environment (1972). Housing and Construction Statistics, No. 1, Tables 20 and 23. London, H.M.S.O.

Duguid, Helen, Simpson, R. G., and Stowers, J. M. (1961). Lancet, 2, 1213. ddy, T. P., Payne, P. R., Salvosa, Carmencita, and Wheeler, Erica F. 1970). Lancet, 2, 1088.

Fox, R. H., Woodward, Patricia M., Fry, A. J., Collins, J. C., and MacDonald, I. C. (1971). Lancet, 1, 424

Fox, R. H., MacGibbon, R., Davies, Louise, and Woodward, Patricia M. (1973a). British Medical fournal, 1, 21

Fox, R. H., Woodward, Patricia M., and MacDonald, I. C. (1973b). In

Ivy, A. C. (1944). Quarterly Bulletin, Northwestern University Medical School, 18, 22.

Kish, L. (1965). Survey Sampling. New York, Wiley

Ministry of Housing and Local Government (1961). Homes for Today and Tomorrow. London, H.M.S.O.

Moser, C. A. (1971). Survey Methods in Social Investigation, 2nd ed. London,

Heinemann.
Office of Population Censuses and Surveys (1972). Cerisus 1971. Advance Analysis. London, H.M.S.O.

Offices, Shops and Railway Premises Act (1963). London, H.M.S.O

Rosin, A. J., and Exton-Smith, A. N. (1964). British Medical fournal, 1, 16. Royal College of Physicians of London (1966). Report of Committee on Accidental Hypothermia. London, R.C.P.

Salvosa, Carmencita, B., Payne, P. R., and Wheeler, Erica F. (1971). British Medical fournal, 4, 656.

Shanas, Ethel, et al. (1968). Old People in Three Industrial Societies. London, Routledge and Kegan Paul.

Society of Medical Officers of Health Hypothermia Sub-Committee of the Welfare Group (i968). Public Health (London), 82, 223.

Welfare Group (1968). Public Health
Taylor, G. (1964). Practitioner, 193, 761.

Watts, A. J. (1972). Environmental Research, 5, 119.

Williams, B. T. (1968). Gerontologia Clinica, 10, 281 